\title{
DOVentYT dispositivo intraoral para facilitar la ventilación con máscara facial
}

\author{
Yépez-Tenía EE. ${ }^{1,2}$, Galaratti D. ${ }^{3,4}$ \\ 1 Hospital Central de Maracay. Maracay, Venezuela. \\ 2 Hospital de Clínicas Caracas. Caracas, Venezuela. \\ 3 Hospital Militar "Cnel. Elbano Paredes Vivas", Maracay, Venezuela. \\ 4 Maracay.
}

Introducción: La ventilación con máscara facial es una técnica de rescate esencial. Se describen situaciones que dificultan la ventilación con máscara, con incidencias de $1,4 \%$ para ventilación difícil con máscara facial y de $0,15 \%$ para ventilación imposible con máscara facial.

Objetivos: Brindar una alternativa para manejo de la ventilación difícil con máscara, desarrollando un dispositivo intraoral denominado DOVentYT, en pacientes bajo protocolo de anestesia general, en Anestesiología del Hospital "Cnel. Elbano Paredes Vivas" de Maracay, estado Aragua.

Métodos: Investigación transversal, de campo, de nivel exploratorio, tipo experimental. La muestra fue de 90 pacientes mayores de 55 años, ambos sexos, sometidos a cirugía electiva o emergencia, Índice de masa corporal > 26, Edéntula, Mallampati III o IV, presencia de barba e historial de ronquidos. Se realizó la captura de datos experimentales durante la fase de inducción anestésica, ventilando al paciente con máscara facial, mascara facial más dispositivo intraoral y máscara facial, dispositivo intra-oral y cánula orofaríngea.

Resultados: Analizando los datos con el programa estadístico IV (IBM) SPSS versión 23, se obtuvo: EtCO2 ventilando con máscara facial $30 \mathrm{mmHg}$, más dispositivo intra-oral ascendió a $32 \mathrm{mmHg}$, con máscara, dispositivo y cánula orofaríngea de $33 \mathrm{mmHg}$. El volumen corriente con máscara facial, se obtuvo una media de 2,00 $\mathrm{ml} / \mathrm{kg}$ de peso, aumentando a $5,45 \mathrm{ml} / \mathrm{kg}$ de peso con el dispositivo y agregando la cánula orofaríngea alcanzó $5,56 \mathrm{ml} / \mathrm{kg}$ de peso. La presión pico de la vía aérea fue de $12 \mathrm{cmsH} 2 \mathrm{O}$ como valor medio con máscara facial, ascendió a $14 \mathrm{cmsH} 2 \mathrm{O}$ con el dispositivo y agregando la cánula orofaríngea fue de $16 \mathrm{cmsH} 2 \mathrm{O}$.

Conclusiones: La innovación DOVentYT, dispositivo intraoral diseñado, mejora los parámetros de ventilación. Para el caso del volumen corriente el aumento, expresado en $\mathrm{ml} / \mathrm{kg}$ de peso, fue de aproximadamente $170 \%$, lo que significa que la entrada y salida de aire a los pulmones es mayor. Los cambios relacionados con el CO2 al final de la espiración fueron de $6 \%$ con el uso del dispositivo respecto a la máscara facial. Con el uso de la cánula orofaríngea aumento $1 \%$ más, lo que resulta en un mejor intercambio gaseoso a nivel alveolar, y por tanto, una mejor ventilación del paciente. Por motivos éticos, no se permitía la desaturación del paciente para hacer el diagnóstico de ventilación difícil, por lo que los cambios con respecto a la SatO2 no fueron tan llamativos, sin embargo se observó un aumento de aproximadamente el $2 \%$ una vez que se agregó el dispositivo a la ventilación.

https://doi.org/10.25237/congresoclasa2019.10 